\title{
Tissue inhibitor of metalloproteinase 1 (TIMP-1) deficiency exacerbates carbon tetrachloride- induced liver injury and fibrosis in mice: involvement of hepatocyte STAT3 in TIMP-1 production
}

Hua Wang ${ }^{1,2}$, Fouad Lafdil ${ }^{2,3}$, Lei Wang ${ }^{2}$, Shi Yin², Dechun Feng ${ }^{2}$ and Bin Gao ${ }^{2 *}$

\begin{abstract}
Background: Tissue inhibitor of metalloproteinase 1 (TIMP-1), which is thought to be produced mainly by activated hepatic stellate cells and Kupffer cells in the liver, plays a pivotal role in matrix remodeling during liver injury and repair; while the effect of TIMP-1 on hepatocellular damage remains obscure.

Results: Hepatic expression of TIMP-1 mRNA and protein was up-regulated both in acute and chronic liver injury induced by carbon tetrachloride $\left(\mathrm{CCl}_{4}\right)$. Compared with wild-type mice, TIMP-1 knockout mice were more susceptible to $\mathrm{CCl}_{4}$-induced acute and chronic liver injury, as shown by higher levels of serum alanine aminotransferase (ALT), greater number of apoptotic hepatocytes, and more extended necroinflammatory foci. TIMP-1 knockout mice also displayed greater degree of liver fibrosis after chronic $\mathrm{CCl}_{4}$ injection when compared with wild-type mice. In vitro treatment with TIMP-1 inhibited cycloheximide-induced cell death of primary mouse hepatocytes. Finally, up-regulation of TIMP-1 in the liver and serum after chronic $\mathrm{CCl}_{4}$ treatment was markedly diminished in hepatocyte-specific signal transducer and activator of transcription 3 (STAT3) knockout mice. In vitro treatment with interleukin-6 stimulated TIMP-1 production in primary mouse hepatocytes, but to a lesser extent in STAT3-deficient hepatocytes.
\end{abstract}

Conclusions: TIMP-1 plays an important role in protecting against acute and chronic liver injury and subsequently inhibiting liver fibrosis induced by $\mathrm{CCl}_{4}$. In addition to activated stellate cells and Kupffer cells, hepatocytes are also responsible for TIMP-1 production during liver injury via a STAT3-dependent manner.

\section{Introduction}

Chronic liver fibrosis induced by viral hepatitis, alcohol abuse, and nonalcoholic steatohepatitis is a major cause of morbidity and mortality worldwide [1]. The progression of liver disease can be defined as an alteration of hepatic parenchyma characterized by two major events: injury and regeneration. The initial cause of the injury determines the loss of hepatocytes including apoptosis and necrosis followed by inflammatory response [2]. Consequently, the loss of tissues or liver injury leads

\footnotetext{
* Correspondence: bgao@mail.nih.gov

${ }^{2}$ Laboratory of Liver Diseases, National Institute on Alcohol Abuse and

Alcoholism, National Institutes of Health, Bethesda, MD 20892, USA

Full list of author information is available at the end of the article
}

viable hepatocytes to re-enter the cell cycle and divide by mitosis, to replace the lost or damaged hepatocytes [3]. During these wound healing processes, the extracellular matrix (ECM) also undergoes a process of remodeling stimulated by persisting inflammatory injury, which may result in abnormal collagen deposition [1]. This microenvironment alteration responsible for hepatocyte damage and ECM remodeling is highly complex and its mechanisms are not fully understood. It seems that all types of liver cells and a variety of soluble factors are involved in the process of ECM remodeling, contributing to hepatocyte injury, inflammation, fibrosis and liver regeneration [4-8]. 
Matrix metalloproteinases (MMPs) and their specific inhibitors, the tissue inhibitors of metalloproteinases (TIMPs) play an important role in inducing and preventing the degradation of the ECM, respectively [9]. Many studies have shown that MMPs and TIMPs play a pivotal role in matrix remodeling during hepatic injury and repair [5,8,10-12]. Among them, TIMP-1 is a widely expressed, and secreted protein that plays a critical role in tissue remodeling via inhibiting members of a large family of MMPs [13]. TIMP-1 has been suggested to be a serum marker for liver fibrosis, and the expression is induced during liver injury [14]. In addition, TIMP-1 also plays an important role in promoting liver fibrosis [15-17] but inhibiting liver regeneration [6]. The profibrogenic effects of TIMP-1 are thought to be mediated via preventing collagen degradation through inhibition of MMPs and protecting against activated hepatic stellate cell (HSC) death [17-20]. It is believed that activated HSCs and Kupffer cells are the major sources for TIMP1 production during liver injury [21]. Although early studies also showed TIMP-1 mRNA and protein expression are up-regulated by inflammatory cytokines in rat hepatocytes $[22,23]$, the precise roles of TIMP-1 produced by hepatocytes in liver injury remain largely unknown. In this study, we found that TIMP-1-deficient (TIMP-1 ${ }^{-1-}$ ) mice were more susceptible to $\mathrm{CCl}_{4}$ induced liver injury and fibrosis, suggesting the protective feature of TIMP-1 in liver injury. Moreover, in vitro experiments showed that TIMP-1 directly protected against cycloheximide-induced hepatocyte death. Lastly, we provided evidence suggesting that hepatocytes also contribute to TIMP-1 production during chronic liver injury, which is controlled by STAT3.

\section{Results}

\section{Up-regulation of TIMP-1 in acute and chronic liver injury} after $\mathrm{CCl}_{4}$ exposure

To determine the expression of TIMP-1 during the course of acute and chronic liver injury, real-time PCR and ELISA analyses were performed on liver samples. As shown in Figure 1A, in a murine model of acute liver injury induced by a single dose of $\mathrm{CCl}_{4}$ injection, hepatic TIMP-1 mRNA expression was markedly up-regulated with a peak $24 \mathrm{~h}$ post $\mathrm{CCl}_{4}$ injection. Serum levels of TIMP-1 protein were also significantly elevated after $\mathrm{CCl}_{4}$ injection, and were maximal $24 \mathrm{~h}$ after injection. Figure 1B shows the hepatic and serum levels of TIMP-1 after a 4-week $\mathrm{CCl}_{4}$ treatment. Expression of TIMP-1 mRNA in the liver was about 30 and 20 folds higher at 24 and $48 \mathrm{~h}$ following the last $\mathrm{CCl}_{4}$ injection, respectively, as compared to corresponding vehicle-treated mice. Similarly, serum levels of TIMP-1 protein were also significantly higher in $\mathrm{CCl}_{4}$-treated mice than in control animals. To further determine the source of TIMP-1 production after $\mathrm{CCl}_{4}$ challenge, immunohistochemistry staining for TIMP-1 in liver tissue sections were performed. Figure $1 \mathrm{C}$ shows that a single injection of $\mathrm{CCl}_{4}$ induced markedly TIMP-1 expression in wild-type mice with predominant expression around necroinflammatory areas and weak staining in hepatocytes, while chronic $\mathrm{CCl}_{4}$ treatment significantly upregulated expression of TIMP-1 in hepatocytes and nonparenchymal cells. As expected, no TIMP-1 expression was detected in TIMP$1^{-/-}$after $\mathrm{CCl}_{4}$ injection. These data show that hepatic and serum levels of TIMP-1 are markedly elevated after acute and chronic $\mathrm{CCl}_{4}$ treatment.

\section{TIMP $-1^{-/-}$mice are more susceptible to acute liver injury} induced by $\mathrm{CCl}_{4}$ administration

Although it has been reported that TIMP-1 plays an important role in liver fibrosis and regeneration [6,15-17], its function during hepatocellular injury remains unclear. Figure 2 compared the acute liver injury induced by a single dose of $\mathrm{CCl}_{4}$ injection between TIMP- ${ }^{-1-}$ and wild-type mice. All animals survived after a single dose of $\mathrm{CCl}_{4}$ challenge. Figure $2 \mathrm{~A}$ show that acute injection of $\mathrm{CCl}_{4}$ administration induced higher levels of serum ALT and AST in TIMP$1^{-1-}$ mice than those in wild-type mice. Consistent with serum ALT levels, TIMP-1 $1^{-1-}$ mice also had larger areas of necrosis than wild-type mice, as assessed by $H \& E$ staining (Figure 2B). In addition, acute $\mathrm{CCl}_{4}$ administration caused necroinflammatory liver damage with foci located predominantly in pericentral regions in wildtype mice, while TIMP-1 ${ }^{-1-}$ mice had a dramatic exacerbation of liver damage with widespread foci of necrotic hepatocytes. Moreover, TUNEL assay shows that TIMP$1^{-/-}$mice had a higher number of apoptotic hepatocytes compared with wild-type mice (Figures 2C-D).

\section{TIMP- ${ }^{-/-}$mice are more susceptible to $\mathrm{CCl}_{4}$-induce chronic liver injury and fibrosis}

It is well established that activation of HSCs is a key event in the pathophysiology of hepatic fibrosis and is accompanied by induction of TIMP-1 [24,25]. In addition, administration of a TIMP-1 antibody attenuated $\mathrm{CCl}_{4}$-induced liver fibrosis [15], thus we hypothesized that deletion of TIMP-1 may reduce liver fibrosis after chronic $\mathrm{CCl}_{4}$ exposure. To test this hypothesis, wild-type and TIMP-1 ${ }^{-1-}$ mice were treated with $\mathrm{CCl}_{4}$ for 4 weeks. Surprisingly, the grade of liver fibrosis was higher in TIMP $-1^{-1-}$ mice with predominant bridging in morphology than that in wild-type mice, which was determined by Sirius red staining for collagen (Figure 3A). Furthermore, immunostaining and Western blot analyses show that expression of $\alpha$-SMA, a marker for HSC activation, was higher in livers from TIMP-1 ${ }^{-1-}$ mice compared with wild-type animals (Figures $3 \mathrm{~B}$ and $3 \mathrm{C}$ ). 


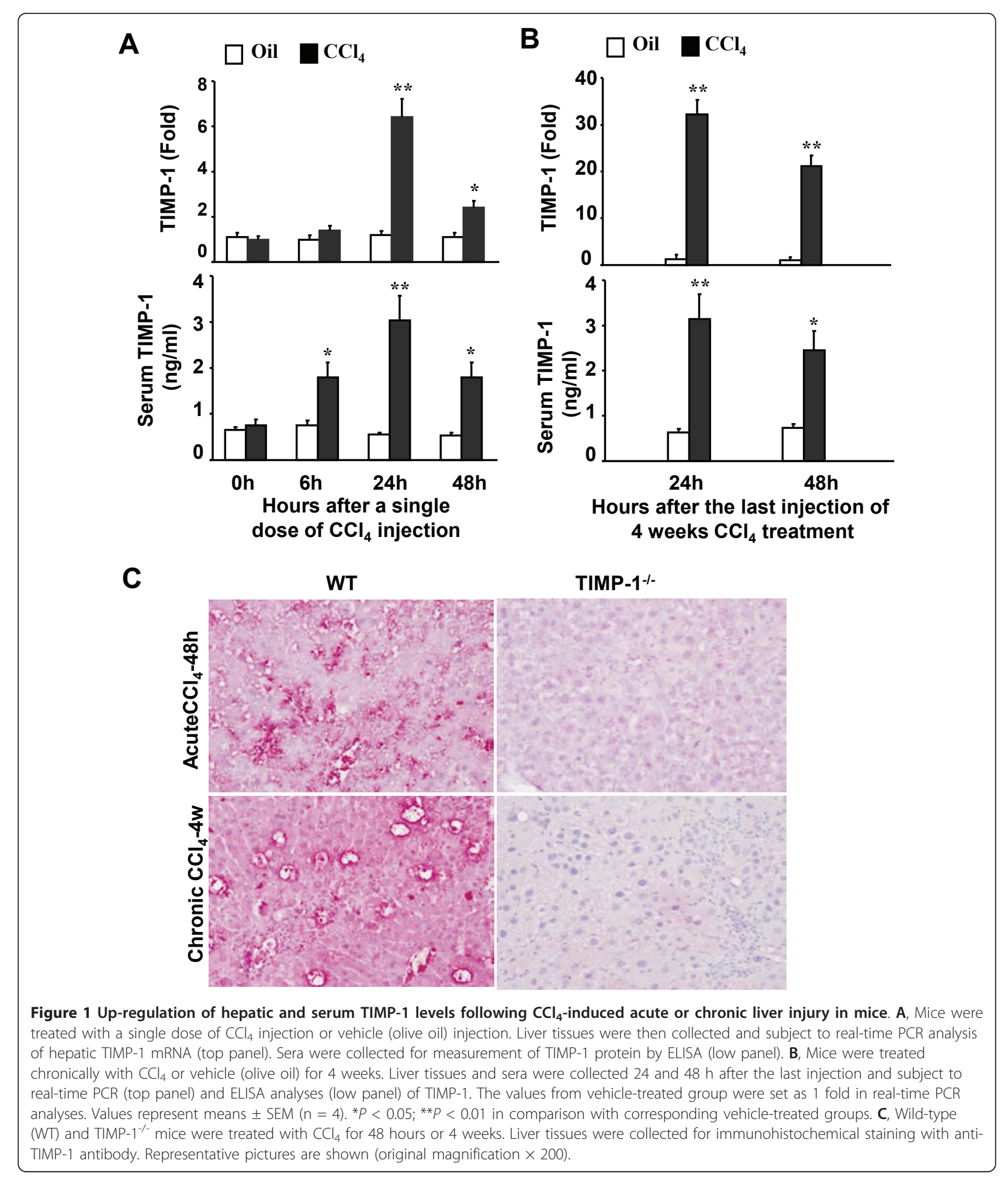

To understand the mechanisms underlying the higher liver fibrosis in TIMP-1 ${ }^{-1-}$ mice than in wild-type mice, the degree of injury was compared between these two strains of mice after chronic $\mathrm{CCl}_{4}$ challenge. In agreement with the greater liver damage in TIMP- $1^{-/-}$ mice after acute $\mathrm{CCl}_{4}$ exposure, repeated exposure of TIMP-1 ${ }^{-1-}$ mice to $\mathrm{CCl}_{4}$ for 4 weeks induced higher levels of ALT, larger area of necrotic hepatocytes, and 
A

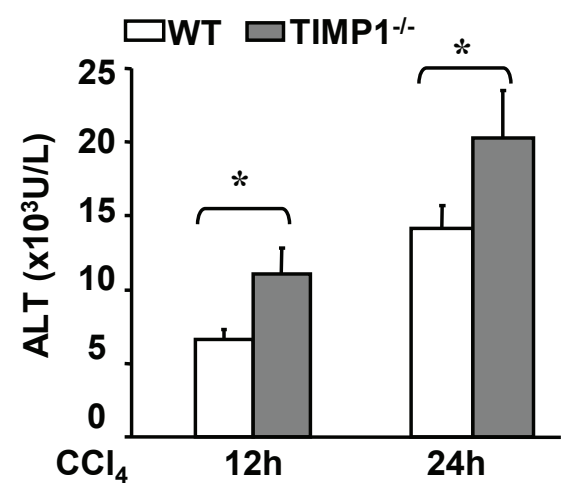

C

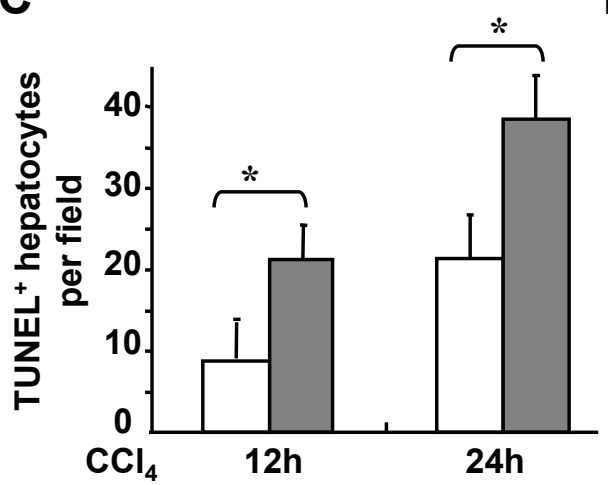

B
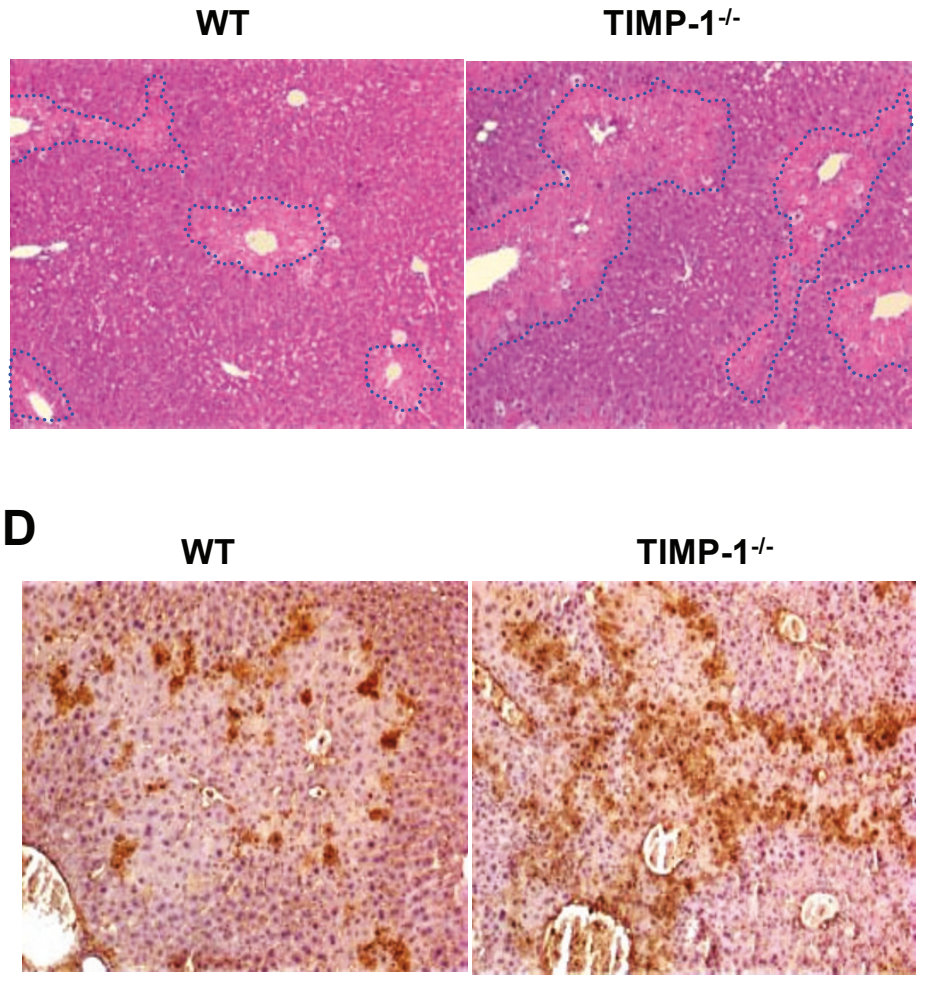

Figure $2 \mathrm{TIMP}_{-1} \mathbf{1}^{-/-}$mice are more susceptible to $\mathrm{CCl}_{4}$-induced acute liver injury. A, B, Wild-type and TIMP-1 ${ }^{-1}$ mice were treated with $\mathrm{CCl}_{4}$ for 12 or 24 hours. Serum ALT levels were assayed (A). The liver tissue sections were stained with H\&E. Representative pictures are shown (original magnification $\times 100)(B)$. C, D, TUNEL positive hepatocytes were counted (C) and representative pictures of TUNEL staining are shown (D). Values represent means \pm SEM $(n=6-10) * P<0.05$

higher number of apoptotic hepatocytes when compared with those in wild-type mice (Figures 4A-B).

TIMP-1 directly protects against hepatocyte death in vitro As TIMP $-1^{-1-}$ mice are more susceptible to $\mathrm{CCl}_{4}$ induced liver injury, we hypothesized that TIMP-1 may protect against hepatocyte death. We further tested this hypothesis in cultured hepatocytes. As illustrated in Figure 5, incubation of primary hepatocytes with cycloheximide induced hepatocyte cell death as evidenced by an increase in AST release. Pretreatment with TIMP-1 significantly prevented cycloheximide-induced hepatocyte death (Figure 5).

\section{IL-6 up-regulates TIMP-1 mRNA and protein in primary cultured hepatocytes via a STAT3-dependent manner} It is believed that TIMP-1 is produced mainly by activated HSCs and Kupffer cells [21], it is not clear whether hepatocytes also contribute to TIMP-1 production. IL- 6 has been shown to up-regulate TIMP-1 expression in HSCs and Kupffer cells [26,27]. Here we also demonstrated that treatment of wild-type mouse hepatocytes with IL-6 markedly up-regulated expression of TIMP-1 mRNA hepatocytes, and reaching its highest level at $6 \mathrm{~h}$ (Figure 6A). TIMP-1 protein levels in the supernatant were also significantly elevated in IL-6treated wild-type hepatocytes compared to those without IL-6 treatment (Figure 6B). Moreover, expression of TIMP-1 mRNA (Figure 6A) and protein (Figure 6B) was markedly lower in the hepatocyte from STAT3 ${ }^{\text {Hep-/- }}$ mice than those from wild-type mice without or with IL-6 treatment.

\section{Deletion of STAT3 in hepatocytes reduces hepatic and} serum levels of TIMP-1 after chronic $\mathrm{CCl}_{4}$ treatment To further confirm the critical role of hepatocyte STAT3 in the induction of TIMP-1 during chronic liver injury in vivo, we compared the production of TIMP-1 between wild-type and STAT3 $3^{\mathrm{Hep}-/-}$ mice 6 and $24 \mathrm{~h}$ after a 4 -week chronic $\mathrm{CCl}_{4}$ treatment. As shown in Figure 7A, hepatic expression of TIMP-1 mRNA was lower in STAT3 ${ }^{\mathrm{Hep}-/-}$ mice as compared to wild-type mice $24 \mathrm{~h}$ after the last $\mathrm{CCl}_{4}$ injection, while the expression of TIMP-2, TIMP-3, and MMP-9 was comparable 


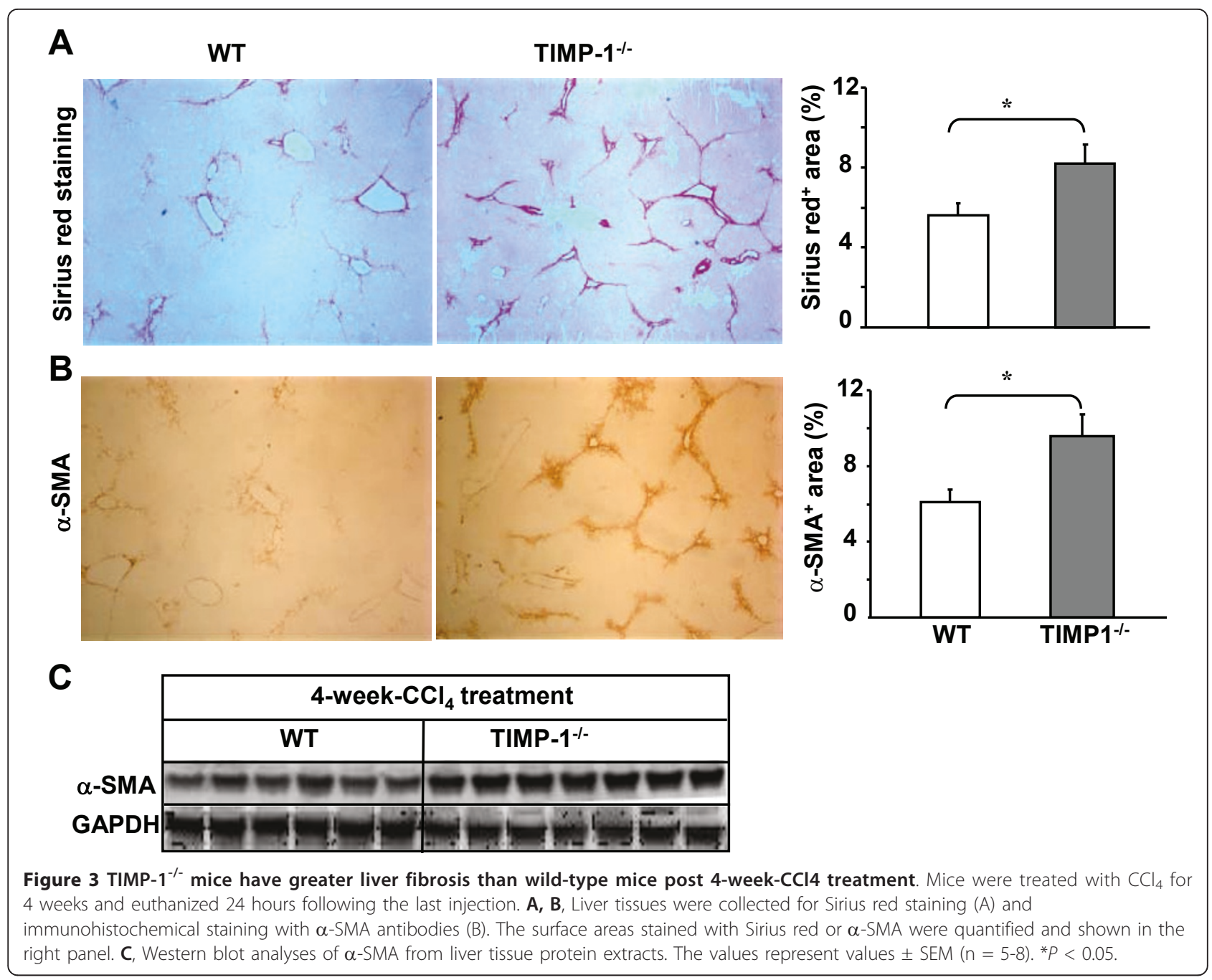

between these 2 groups. Serum levels of TIMP-1 protein were also lower in STAT3 ${ }^{\mathrm{Hep}-1-}$ mice $24 \mathrm{~h}$ and $48 \mathrm{~h}$ post the last injection of $\mathrm{CCl}_{4}$ than those in wild-type mice (Figure 7B).

\section{Discussions}

Although the profibrotic effect of TIMP-1 mainly produced by HSCs has been well documented [15,19], we reveal here for the first time an unexpected hepatoprotective feature of TIMP-1 and contribution of hepatocytes to TIMP-1 production during $\mathrm{CCl}_{4}$-induced liver injury.

\section{Hepatoprotection of TIMP-1: dual roles of TIMP-1 in liver} fibrosis

TIMP- $1^{-/-}$mice were more susceptible to hepatocelluar damage induced by $\mathrm{CCl}_{4}$ treatment, suggesting that TIMP-1 plays a hepatoprotective role during liver injury. Such hepatoprotection is mediated, at least in part, via directly inhibiting hepatocyte death as TIMP-1 treatment prevented cycloheximide-induced hepatocyte damage (Figure 5). At the present, the mechanism underlying TIMP-1 hepatoprotection remains unknown. TIMP-1 is a survival factor for many cell types dependent and/or independent of the MMP-inhibitory activity [13]. For example, TIMP-1 inhibits HSC apoptosis via MMP inhibition [19], while the anti-apopotic effect of TIMP-1 on human breast carcinoma cells does not require MMP inhibition [28]. Further studies will be required to investigate the mechanism underlying the anti-apoptotic effect of TIMP-1 on hepatocytes.

TIMP-1 has been suggested as a profibrogenic factor to promote liver fibrosis as liver-specific TIMP-1 transgenic mice were resistant to fibrosis resolution [16] and TIMP-1 neutralizing antibody inhibited liver fibrosis [15]. However, surprisingly, TIMP $-1^{-/-}$mice developed greater fibrosis compared with wild-type mice after $\mathrm{CCl}_{4}$. challenge (Figure 3). As TIMP-1 protects against HSC death [19] and hepatocyte apoptosis (Figure 5), we speculate that TIMP-1 may have dual roles in liver fibrosis: 


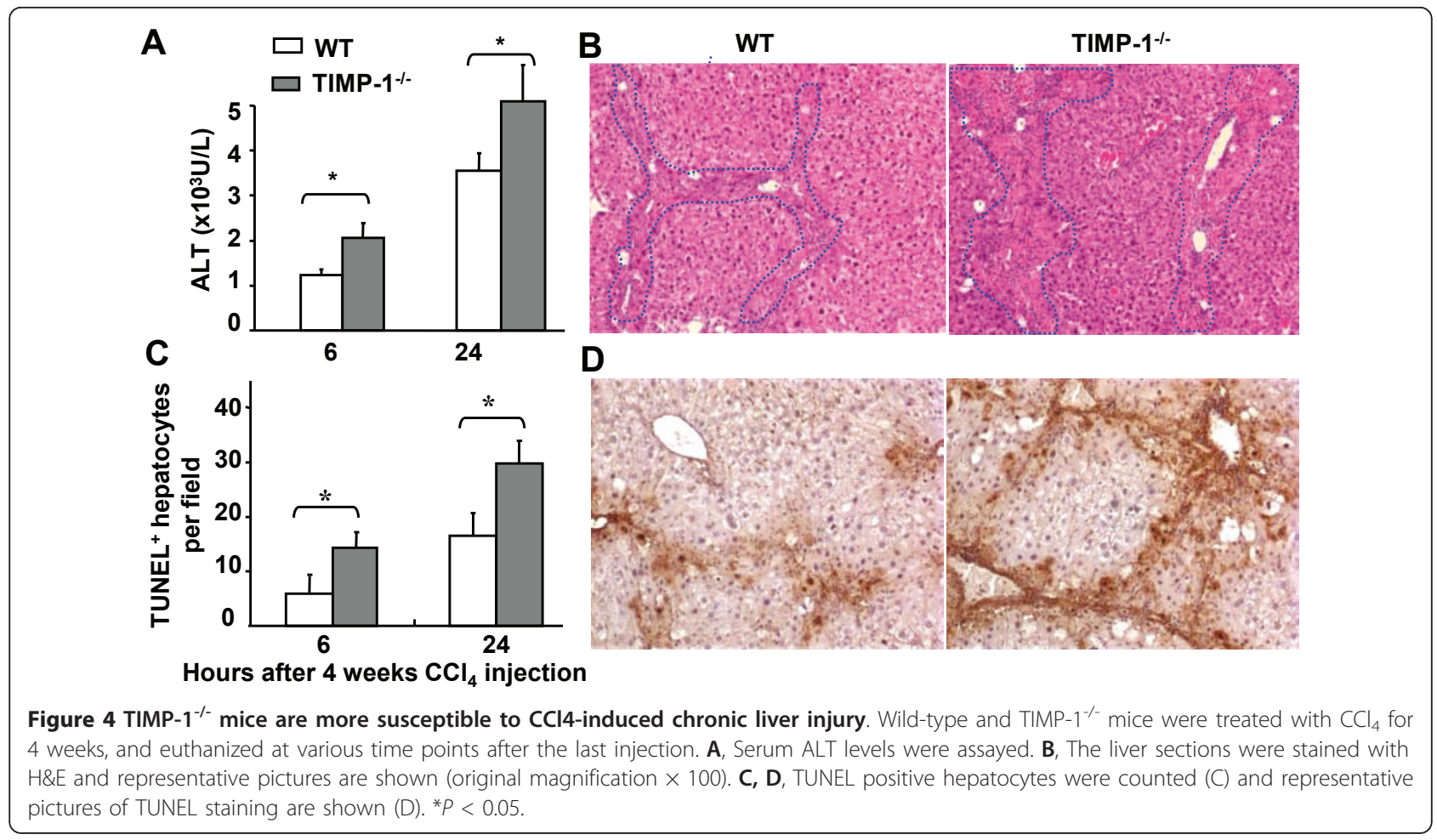

stimulating liver fibrosis via promoting HSC survival and inhibiting liver fibrosis via preventing liver injury. The final effect of TIMP-1 on liver fibrosis is determined by the balance between these stimulatory and inhibitory effects. Deletion of TIMP-1 may reduce liver fibrosis through abolishing the profibrogenic effect of

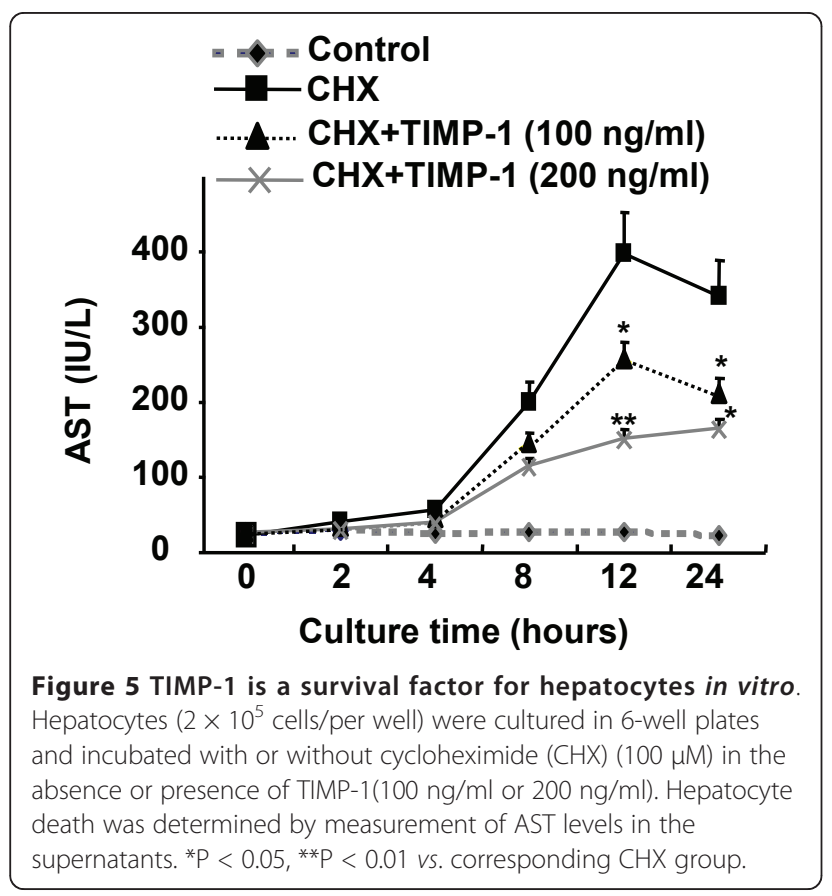

TIMP-1, but may also accelerate liver fibrosis by increasing liver injury. Acceleration of liver fibrosis by increased liver injury in TIMP-1 ${ }^{-1-}$ mice may dominate over the profibrogenic effect of TIMP-1 on liver fibrosis, leading to greater liver fibrosis in TIMP $-1^{-1-}$ mice after $\mathrm{CCl}_{4}$ treatment.

Hepatocytes contribute to TIMP-1 production during liver injury: controlled by STAT3

Expression of TIMP-1 is induced in the liver during liver injury. It is generally believed that activated HSCs and Kupffer cells are the major source of TIMP-1 production as strong TIMP-1 immunostaining was detected in activated HSCs and Kupffer cells [21]. Our findings here suggest that hepatocytes also contribute significantly to TIMP-1 production that is controlled by STAT3. As shown in Figure 7, serum and hepatic levels of TIMP-1 were lower in STAT3 ${ }^{\mathrm{Hep}-1-}$ mice, suggesting that activation of STAT3 in hepatocytes plays an important role in induction of TIMP-1 during liver injury. This induction is likely due to the direct stimulation of TIMP-1 production in hepatocytes by STAT3 as in vitro IL-6 treatment induced TIMP-1 production in cultured hepatocytes [23,29] and such induction was diminished in STAT3-deficient hepatocytes (Figure 6). In addition, STAT3 binding sites were found on TIMP-1 promoter [30], providing a molecular basis for STAT3-mediated induction of TIMP-1. Finally, the conclusive evidence for contribution of hepatocytes to TIMP-1 production is 


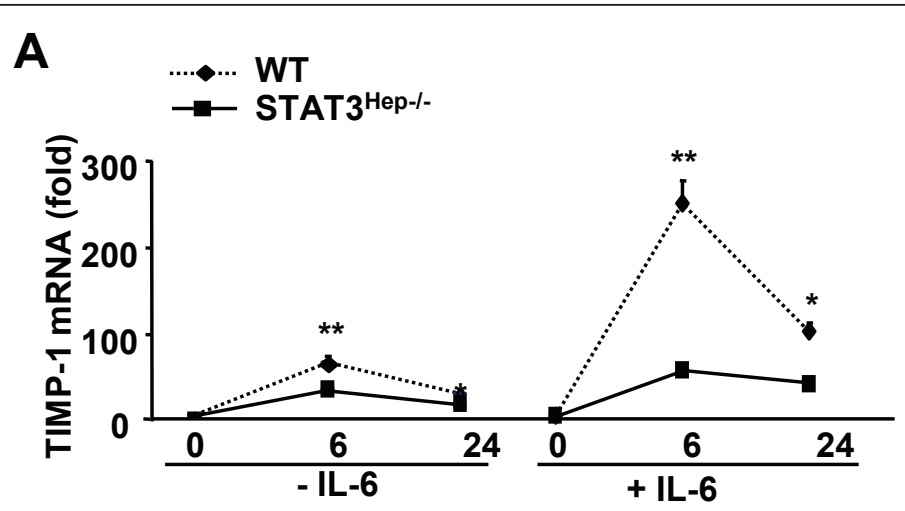

B

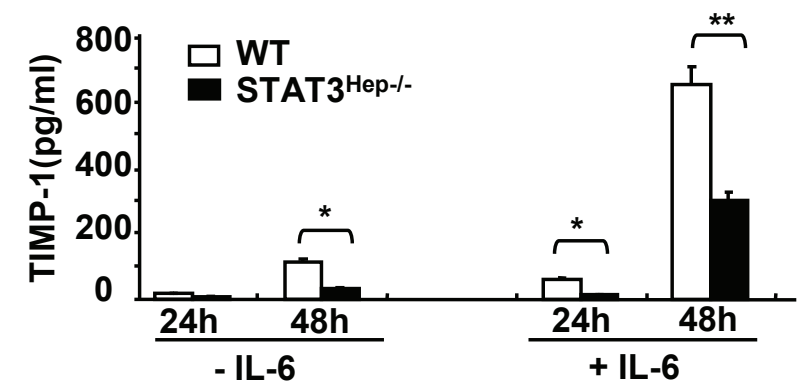

Figure 6 IL-6 induction of TIMP-1 in primary hepatocytes is mediated via a STAT3-dependent mechanism. A, Hepatocytes $\left(2 \times 10^{5}\right.$ cells/

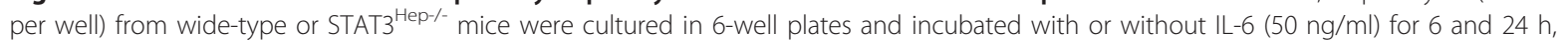
followed by real-time PCR analysis of TIMP-1 mRNA, B, or cultured for 24 and 48 h, followed by collection of the supernatants for measurement of TIMP-1 protein. Values are means \pm SE from 4 independent experiments. ${ }^{*} P<0.05$, and ${ }^{* *} P<0.01$ in comparison with the corresponding wild-type groups.
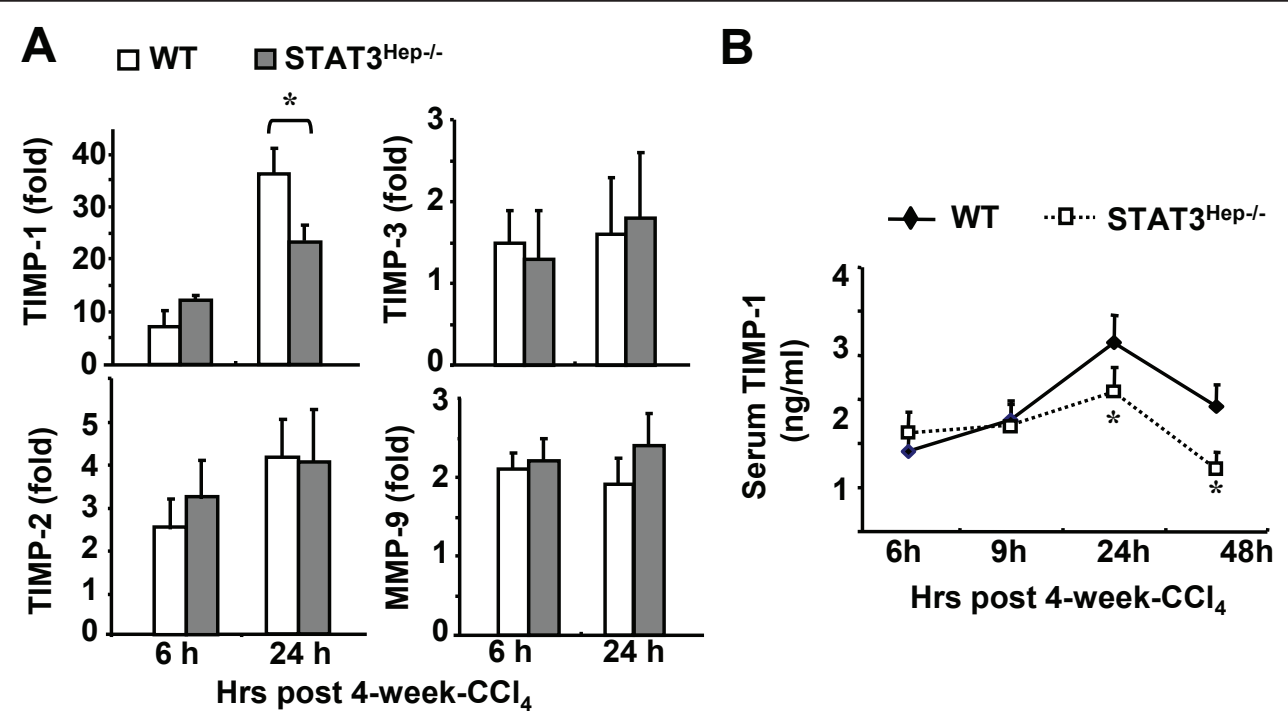

Figure 7 TIMP-1 production is reduced in STAT3 ${ }^{\text {Hep-/- }}$ mice during chronic liver injury. A, Mice were treated with $\mathrm{CCl}_{4}$ for 4 weeks and euthanized at various time points. Liver tissues were collected and analyzed for TIMP-1, TIMP-2, TIMP-3 and MMP-9. Value from wild-type mice without $\mathrm{CCl}_{4}$ treatment was set as 1. B, Serum levels of TIMP-1 protein at various time points post 4-week-CCl treatment. $^{*} P<0.05$ in comparison with the corresponding wild-type groups. 
that TIMP-1 was stained strongly in hepatocytes from the livers of mice with acute and chronic $\mathrm{CCl}_{4}$ treatment. Collectively, these findings suggest that in addition to HSCs and Kupffer cells, hepatocytes are also a source for TIMP-1 production which is controlled partially by STAT3 during chronic liver injury.

In summary, our observations collectively identify newly hepatoprotective role of TIMP-1 in a positive feedback manner during liver injury, which is regulated by IL-6/STAT3 signaling pathway. TIMP-1 plays dual roles in regulating liver fibrosis by inhibiting liver fibrosis via protecting against liver injury or by promoting liver fibrosis via protecting against HSC death.

\section{Materials and methods}

Mice

Eight- to ten-week-old male TIMP- $1^{-/-}$mice and their wild-type control C57BL/6 mice were purchased from the Jackson laboratory (Bar Harbor, Maine). Hepatocytespecific STAT3 knockout mice (AlbCre ${ }^{+/-}$STAT3 $^{\text {flox/flox }}$ ) $\left(\mathrm{STAT} 3^{\mathrm{Hep}-/-}\right)$ and their littermate wild-type controls (AlbCre-STAT3 $3^{\text {flox/flox }}$ ) were described previously [31]. All animal experiments were approved by the Institutional Animal Care and Use Committee of the NIAAA.

\section{$\mathrm{CCl}_{4}$-induced liver injury}

For acute $\mathrm{CCl}_{4}$-induced liver injury, mice were injected (i.p) with a single dose of $\mathrm{CCl}_{4}(2 \mathrm{ml} / \mathrm{kg}$ body weight of $10 \% \mathrm{CCl}_{4}$ dissolved in olive oil). For chronic $\mathrm{CCl}_{4}$ studies, mice received $\mathrm{CCl}_{4}$ injection $(2 \mathrm{ml} / \mathrm{kg}$ body weight of $\left.10 \% \mathrm{CCl}_{4}\right) 3$ times a week for up to 4 weeks. Control groups were treated with vehicle (100\% olive oil, $2 \mathrm{ml} /$ $\mathrm{kg}$ ). In chronic studies, the mice were sacrificed at different time points after the last injection of chronic $\mathrm{CCl}_{4}$ treatment.

\section{Blood chemistry}

Serum alanine transaminase (ALT) and aspartate aminotransferase (AST) were determined using a chemistry analyzer (PROCHEM-V; Barrow-in-Furness, UK). Serum TIMP-1 levels were assessed by Quantikine enzymelinked immunosorbent assay (ELISA) kits (R\&D Systems, Minneapolis, MN).

\section{Histological analysis}

Formalin-fixed liver samples were processed, and paraffinembedded liver tissue sections were stained with hematoxylin and eosin (H\&E). Liver fibrosis was determined by Sirius Red staining for collagens or immunohistochemical staining for activated HSCs with anti- $\alpha$-smooth muscle actin ( $\alpha$-SMA) (Dako, Carpinteria, CA), and were quantified by digital imaging with NIH Scion Image and Adobe Photoshop (San Jose, CA). Expression of TIMP-1 in the liver was measured by immunohistochemical staining with anti-TIMP-1 antibody (R\&D Systems).

\section{TUNEL assay}

Hepatocyte apoptosis was detected by using an Apoptag Apoptosis Detection Kit (Chemicon International, Temecula, CA) as previously described [32].

\section{Real Time PCR}

Total RNA was purified from about 30 mg liver samples according to the manufacturer (Qiagen, Valencia, CA) and then $1 \mu \mathrm{g}$ mRNA was reverse-transcribed to cDNA using a High Capacity cDNA Reverse Transcription kit (Invitrogen, Carlsbad, CA). The cDNA template was diluted 1:5 and amplified in real-time PCR using iTaq SYBR Green Supermix (Bio-rad, Hercules CA). An initial denaturation at $95^{\circ} \mathrm{C}$ for 3 min was followed with PCR cycling: $95^{\circ} \mathrm{C}(15 \mathrm{sec})$, and $58^{\circ} \mathrm{C}(30 \mathrm{sec})$ for 40 cycles. Relative mRNA levels were calculated by means of $2^{-\Delta \Delta C T}(\Delta \Delta C T=$ difference of crossing points of test samples and respective control samples as extracted from amplification curves by the LightCycler software) after normalization to $18 \mathrm{~S}$ expression used as an internal standard. Fold inductions of analyzed mRNA expression were normalized on $18 \mathrm{~S}$ RNA expression. The sequences of primers were described previously [31].

\section{Western blotting}

Liver homogenates were prepared in RIPA buffer (50 mM Tris; 1\% NP40; 0.25\% Deoxycholic acid sodium salt; $150 \mathrm{mM} \mathrm{NaCl} ; 1 \mathrm{mM}$ EGTA) containing $1 \mathrm{mM}$ $\mathrm{Na}_{3} \mathrm{VO}_{4}$ and a protease inhibitor cocktail (Sigma, St. Louis, MO). Protein concentrations were quantified with a detergent compatible protein assay kit (Bio-Rad Laboratories) according to the manufacture's manual. Fifty $\mu \mathrm{g}$ of total protein extracts were denatured in Laemmli buffer containing $5 \% \beta$-mercaptoethanol, then loaded and separated by gel electrophoresis on a $7 \%$ Bis-Tris gel (Invitrogen). Primary antibody was incubated at $4^{\circ} \mathrm{C}$ overnight under shaking conditions. Immunoreactive bands were visualized on nitrocellulose membranes using alkaline-phosphotase-linked antimouse or rabbit antibody and the ECF detection system with a PhosphorImager (GE Healthcare, Piscataway, NJ). Mouse monoclonal anti- $\alpha$-SMA antibody was obtained from Sigma-Aldrich. Mouse monoclonal anti-GAPDH antibody was obtained from Cell Signaling Technology (Danvers, MA).

\section{Hepatocyte culture and treatment}

Mouse hepatocytes were isolated by in situ collagenase perfusion method [31]. Hepatocytes $\left(2 \times 10^{5}\right.$ cells/per well) were cultured in 6-well plates with serum-free 
medium and treated with IL-6 $(50 \mathrm{ng} / \mathrm{ml})$, followed by the measurement of TIMP-1 protein in culture medium. The hepatocytes were also cultured in medium containing $5 \%$ serum and treated with cycloheximide $(100 \mu \mathrm{M})$ (Sigma) in the presence or absence of recombinant murine TIMP-1 $(100 \mathrm{ng} / \mathrm{ml}$ or $200 \mathrm{ng} / \mathrm{ml})$. Cycloheximide was used to induce hepatocyte apoptosis. Hepatocyte death was quantified by measuring the activity of released AST in culture medium.

\section{Statistical Analysis}

Data are expressed as means \pm SEM $(\mathrm{N}=5-12$ in each group). Student $t$ test was performed to compare values from 2 groups. To compare values obtained from three or more groups, 1-factor analysis of variance (ANOVA) was used, followed by Tukey's post hoc test. Statistical significance was taken at the $P<0.05$ level.

\section{List of Abbreviations}

ALT: alanine transaminase; AST: aspartate aminotransferase; $\mathrm{CCl}_{4}$ : carbon tetrachloride; STAT: signal transducer and activator of transcription; STAT3 ${ }^{\text {Hep- }}$ mice: hepatocyte-specific STAT3 knockout mice; MMP: Matrix metalloproteinase; TIMP: tissue inhibitor of metalloproteinase; WT: wild-type mice.

\section{Acknowledgements}

This work was supported in part by the intramural program of NIAAA, NIH (B Gao) and in part by the Natural Science Foundation of China ( $H$ Wang, No. 30973467/H1611).

\section{Author details}

'Department of Oncology, The Affiliated Provincial Hospital of Anhui Medical University, Hefei, Anhui 230001, PR China. ² Laboratory of Liver Diseases, National Institute on Alcohol Abuse and Alcoholism, National Institutes of Health, Bethesda, MD 20892, USA. ${ }^{3}$ Laboratory of Liver Pathophysiology, INSERM U955, Hopital Henri Mondor, 94010 Creteil Cedex, France.

\section{Authors' contributions}

HW participated in its design, carried out most of experiments, and drafted the manuscript. FL, LW and SY carried $\mathrm{CCl}_{4}$ injection, tissue collection, and hepatocyte isolation. DF performed immunohistochemistry analyses of TIMP1. BG conceived of the study, participated in its design and coordination, and edited the manuscript. All authors read and approved the final manuscript.

\section{Competing interests}

The authors declare that they have no competing interests.

Received: 10 January 2011 Accepted: 4 April 2011

Published: 4 April 2011

\section{References}

1. Friedman SL: Evolving challenges in hepatic fibrosis. Nat Rev Gastroenterol Hepatol 2010, 7:425-436.

2. Malhi H, Guicciardi ME, Gores GJ: Hepatocyte death: a clear and present danger. Physiol Rev 2010, 90:1165-1194.

3. Michalopoulos GK: Liver regeneration after partial hepatectomy: critical analysis of mechanistic dilemmas. Am J Pathol 2010, 176:2-13.

4. Roderfeld M, Hemmann S, Roeb E: Mechanisms of fibrinolysis in chronic liver injury (with special emphasis on MMPs and TIMPs). $Z$ Gastroenterol 2007, 45:25-33.

5. Consolo M, Amoroso A, Spandidos DA, Mazzarino MC: Matrix metalloproteinases and their inhibitors as markers of inflammation and fibrosis in chronic liver disease (Review). Int J Mol Med 2009, 24:143-152.
6. Mohammed FF, Pennington CJ, Kassiri Z, Rubin JS, Soloway PD, Ruther U, et al: Metalloproteinase inhibitor TIMP-1 affects hepatocyte cell cycle via HGF activation in murine liver regeneration. Hepatology 2005, 41:857-867.

7. Manicone AM, McGuire JK: Matrix metalloproteinases as modulators of inflammation. Semin Cell Dev Biol 2008, 19:34-41.

8. Hemmann S, Graf J, Roderfeld M, Roeb E: Expression of MMPs and TIMPs in liver fibrosis - a systematic review with special emphasis on antifibrotic strategies. J Hepatol 2007, 46:955-975.

9. Kessenbrock K, Plaks V, Werb Z: Matrix metalloproteinases: regulators of the tumor microenvironment. Cell 2010, 141:52-67.

10. Dechene A, Sowa JP, Gieseler RK, Jochum C, Bechmann LP, El Fouly A, et al: Acute liver failure is associated with elevated liver stiffness and hepatic stellate cell activation. Hepatology 2010, 52:1008-1016.

11. Madala SK, Pesce JT, Ramalingam TR, Wilson MS, Minnicozzi S, Cheever AW, et al: Matrix metalloproteinase 12-deficiency augments extracellular matrix degrading metalloproteinases and attenuates IL-13-dependent fibrosis. J Immunol 2010, 184:3955-3963.

12. Defamie V, Laurens M, Patrono D, Devel L, Brault A, Saint-Paul MC, et al: Matrix metalloproteinase inhibition protects rat livers from prolonged cold ischemia-warm reperfusion injury. Hepatology 2008, 47:177-185.

13. Chirco R, Liu XW, Jung KK, Kim HR: Novel functions of TIMPs in cell signaling. Cancer Metastasis Rev 2006, 25:99-113.

14. Nobili V, Parkes J, Bottazzo G, Marcellini M, Cross R, Newman D, et al: Performance of ELF serum markers in predicting fibrosis stage in pediatric non-alcoholic fatty liver disease. Gastroenterology 2009, 136:160-167.

15. Parsons CJ, Bradford BU, Pan CQ, Cheung E, Schauer M, Knorr A, et al: Antifibrotic effects of a tissue inhibitor of metalloproteinase- 1 antibody on established liver fibrosis in rats. Hepatology 2004, 40:1106-1115.

16. Yoshiji H, Kuriyama S, Yoshii J, Ikenaka Y, Noguchi R, Nakatani T, et al: Tissue inhibitor of metalloproteinases-1 attenuates spontaneous liver fibrosis resolution in the transgenic mouse. Hepatology 2002, 36:850-860.

17. Gieling RG, Burt AD, Mann DA: Fibrosis and cirrhosis reversibility molecular mechanisms. Clin Liver Dis 2008, 12:915-937, xi.

18. Friedman SL: Mechanisms of hepatic fibrogenesis. Gastroenterology 2008 , 134:1655-1669.

19. Murphy FR, Issa R, Zhou X, Ratnarajah S, Nagase H, Arthur MJ, et al: Inhibition of apoptosis of activated hepatic stellate cells by tissue inhibitor of metalloproteinase-1 is mediated via effects on matrix metalloproteinase inhibition: implications for reversibility of liver fibrosis. J Biol Chem 2002, 277:11069-11076.

20. Iredale JP: Tissue inhibitors of metalloproteinases in liver fibrosis. Int J Biochem Cell Biol 1997, 29:43-54.

21. Jeong WI, Do SH, Jeong DH, Hong IH, Park JK, Ran KM, et al: Kinetics of MMP-1 and MMP-3 produced by mast cells and macrophages in liver fibrogenesis of rat. Anticancer Res 2006, 26:3517-3526.

22. Roeb E, Graeve L, Hoffmann R, Decker K, Edwards DR, Heinrich PC: Regulation of tissue inhibitor of metalloproteinases-1 gene expression by cytokines and dexamethasone in rat hepatocyte primary cultures. Hepatology 1993, 18:1437-1442.

23. Roeb E, Graeve L, Mullberg J, Matern S, Rose-John S: TIMP-1 protein expression is stimulated by IL-1 beta and IL- 6 in primary rat hepatocytes. FEBS Lett 1994, 349:45-49.

24. Bahr MJ, Vincent KJ, Arthur MJ, Fowler AV, Smart DE, Wright MC, et a : Control of the tissue inhibitor of metalloproteinases-1 promoter in culture-activated rat hepatic stellate cells: regulation by activator protein-1 DNA binding proteins. Hepatology 1999, 29:839-848.

25. Nieto N, Dominguez-Rosales JA, Fontana L, Salazar A, ArmendarizBorunda J, Greenwel P, et al: Rat hepatic stellate cells contribute to the acute-phase response with increased expression of alpha1(I) and alpha1 (IV) collagens, tissue inhibitor of metalloproteinase-1, and matrixmetalloproteinase-2 messenger RNAs. Hepatology 2001, 33:597-607.

26. Nieto N: Oxidative-stress and IL-6 mediate the fibrogenic effects of [corrected] Kupffer cells on stellate cells. Hepatology 2006, 44:1487-1501.

27. Bugno M, Graeve L, Gatsios P, Koj A, Heinrich PC, Travis J, et al: Identification of the interleukin-6/oncostatin $\mathrm{M}$ response element in the rat tissue inhibitor of metalloproteinases-1 (TIMP-1) promoter. Nucleic Acids Res 1995, 23:5041-5047.

28. Lee SJ, Yoo HJ, Bae YS, Kim HJ, Lee ST: TIMP-1 inhibits apoptosis in breast carcinoma cells via a pathway involving pertussis toxin-sensitive $G$ protein and c-Src. Biochem Biophys Res Commun 2003, 312:1196-1201. 
29. Richards CD, Kerr C, Tanaka M, Hara T, Miyajima A, Pennica D, et al: Regulation of tissue inhibitor of metalloproteinase- 1 in fibroblasts and acute phase proteins in hepatocytes in vitro by mouse oncostatin $M$, cardiotrophin-1, and IL-6. J Immunol 1997, 159:2431-2437.

30. Lin S, Saxena NK, Ding X, Stein LL, Anania FA: Leptin increases tissue inhibitor of metalloproteinase I (TIMP-1) gene expression by a specificity protein 1/signal transducer and activator of transcription 3 mechanism. Mol Endocrinol 2006, 20:3376-3388.

31. Horiguchi N, Wang L, Mukhopadhyay P, Park O, Jeong WI, Lafdil F, et al: Cell type-dependent pro- and anti-inflammatory role of signal transducer and activator of transcription 3 in alcoholic liver injury. Gastroenterology 2008, 134:1148-1158.

32. Jeong WI, Park O, Gao B: Abrogation of the antifibrotic effects of natural killer cells/interferon-gamma contributes to alcohol acceleration of liver fibrosis. Gastroenterology 2008, 134:248-258.

doi:10.1186/2045-3701-1-14

Cite this article as: Wang et al:: Tissue inhibitor of metalloproteinase 1 (TIMP-1) deficiency exacerbates carbon tetrachloride-induced liver injury and fibrosis in mice: involvement of hepatocyte STAT3 in TIMP-1 production. Cell \& Bioscience 2011 1:14.

\section{Submit your next manuscript to BioMed Central} and take full advantage of:

- Convenient online submission

- Thorough peer review

- No space constraints or color figure charges

- Immediate publication on acceptance

- Inclusion in PubMed, CAS, Scopus and Google Scholar

- Research which is freely available for redistribution

Submit your manuscript at www.biomedcentral.com/submit
C Biomed Central 